Int. J. Dev. Biol. 59: 51-54 (2015)

doi: $10.1387 / \mathrm{ijdb} .150063 \mathrm{fk}$

\title{
Multifaceted programmed cell death in the mammalian fetal ovary
}

\author{
FRANCESCA G. KLINGER*, VALERIO ROSSI and MASSIMO DE FELICI \\ Department of Biomedicine and Prevention, University of Rome Tor Vergata, 00133, Rome, Italy
}

\begin{abstract}
From previous and more recent works reviewed in the present paper, it appears that mammalian fetal oocytes face several challenges to survive throughout the stages of meiotic prophase I up to the block at the diplotene/dictyate stage and the primordial follicle assembly. Depending on the period of development and experimental conditions, these oocytes can undergo different forms of programmed cell death (PCD) and cross-talking pathways. We hypothesize that they require the continuous support of growth factors to accomplish the activities required to overcome PCD during prophase I. An extraordinary level of DNA double strand break (DSB) tolerance characterizes oocytes during the first stages of meiotic prophase I. However, the activation of a p63/p53-and PCNA-dependent DNA damage checkpoint, plays a major role in eliminating defective oocytes when they reach the diplotene stage. Before oocytes are enclosed into a primordial follicle, the shortness of nutrients/growth factors might activate protective autophagy but this can turn into their death if starvation is prolonged. Actually, clarifying the relationships among growth factor signalling (mainly AKT cascade), apoptotic and autophagic proteins that seem to coexist in fetal oocytes, could be the key to understanding PCD in these cells.
\end{abstract}

KEY WORDS: apoptosis, fetal ovary, oocyte, autophagy

\section{Introduction}

For many aspects, the mammalian ovary is still a mysterious organ, in particular concerning the processes that throughout the life lead to the exhaustion of the follicles and the internal oocyte population. Actually, in all mammalian species, the fertility lifespan of the females appears limited by an unavoidable decrease of the follicle pool. For a long time, scientists were aware that granulosa cells and oocytes undergo massive death physiologically and/ or following pathological and environment conditions. However, the mechanisms of such process remained obscure until 1970s, when they begin to realize that the granulosa cell and oocyte death represented a paradigm of the multiple faces of the programmed cell death (PCD).

During the female germ cell development, the shift from mitosis to meiosis, the progression through the meiotic prophase I stages and the formation of primordial follicles, are crucial events within the fetal or early postnatal ovary during which oocytes undergo massive PCD. Later, in the prepuberal and adult ovary, while the most part of oocytes within the primordial follicles (ovarian reserve) avoid death for long periods (several years in humans), a subset of them is continuously engaged in folliculogenesis leading many to death and a few to fully maturation and eventually fertilization.

An extensive recent report and discussion about the principal studies concerning oocyte death in the fetal and early postnatal mammalian ovaries can be found elsewhere (Klinger and De Felici, 2011; De Felici and Klinger, 2011).

In the present paper, we will limit our review to the most relevant new results obtained on this topic in the last few years and will discuss them with the aim to give the readers an up- to-date view of the progress made in this field.

\section{Timing and causes of oocyte PCD}

Although female germ cells can continuously undergo death during prenatal and early postnatal periods, more pronounced waves of degeneration have been described during the shift from mitotic primordial germ cells/oogonia and meiotic oocytes, in oocytes at

Abbreviations used in this paper: AAPC/C, anaphase promoting complex C; DSB, double strand break; LINE-1, long interspersed element 1; MCL-1, myeloid cell leukemia-1; PARP-1, cleaved poly (ADP-ribose) polymerase-1; PCD, programmed cell death; PCNA, proliferating cell nuclear antigen; XIAP, X-linked inhibitor of apoptosis protein.

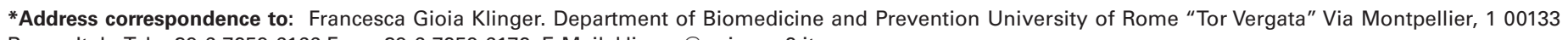
Rome, Italy.Tel: +39-6-7259-6166 Fax: +39-6-7259-6172. E-Mail: klinger@uniroma2.it
}

Accepted: 6 May 2015.

ISSN: Online 1696-3547, Print 0214-6282 
the final stages of meiotic prophase I (pachytene/diplotene) and at the breakdown of the oocyte nests preluding the primordial follicle assembly. Such waves lead to the massive decrease of the oocyte number that characterizes early mammalian oogenesis. At least in human and mouse, oocyte extrusion from the ovary surface observed at perinatal stages might contribute to such depletion (Rodrigues et al., 2009, and references herein).

While at the shift from mitosis to meiosis, female germ cell degeneration might occur for defects in the unknown mechanisms underlying this crucial event, at later stages, three main causes of death of meiotic oocytes have been proposed: 1) an excess of oocyte number respect to the available nutrients/growth factors and/ or to the number of the supporting ovarian somatic cells (death by neglect), 2) incomplete DNA repair or errors in chromosome synapses occurring throughout meiotic prophase I (death by defects) and 3) self-sacrifice of oocytes donating their cytoplasm content to a subset of surviving oocytes at the breakdown of the oocyte nests leading to the follicle assembly (death by self-sacrifice) (Tilly, 2001). Recent papers have shown that during the prophase I, other causes of PCD in mouse oocytes can be compromised autophagy, defect in APC/C activity and transposon jumping. Actually, Gawriluk et al., (2011), showed that the ablation of the genes encoding two major players of autophagy such as beclin1 or autophagy-related protein 7 (ATG7), resulted in a marked decrease of the oocyte number after birth. Unfortunately, in this work the characteristics of the death and possible loss of oocytes in the fetal ovary were not investigated. According to Holt and coll. (Holt et al., 2014), defects in the activation of the APC/C complex necessary for the zygotene-pachytene transition, as a consequence of Fizzy-related (Fzr1) gene ablation, can lead to oocyte apoptosis. Finally, Malki et al.,2014), showed that many oocytes were eliminated at the end of prophase I as a consequence of DNA damage generated by long interspersed element1 (LINE-1) retrotransposons, activated during epigenetic reprogramming of the embryonic germline. The authors did not characterized the oocyte death, but suggested that this process serves to select oocytes with limited LINE-1 activity that are therefore best suited for the next generation.

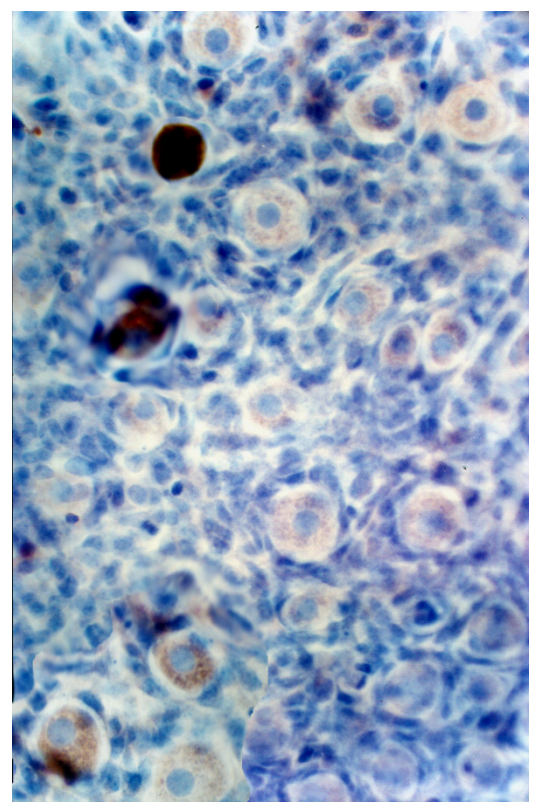

Fig. 1. Expression of BAX in meiotic prophase I mouse oocytes. Immunohistochemistry for $B A X$ revealing different expression levels in oocytes within ovarian tissue fragments obtained from $14.5 \mathrm{dpc}$ mouse ovaries and cultured for about one week as reported in Pesce et al., (1996); while $B A X$ was expressed at moderate levels in the most part of oocytes, more intense staining was observed in a subset of oocytes likely undergoing apoptosis.

\section{Mechanisms of oocyte PCD}

\section{Apoptotic markers}

It is now largely accepted that whatever the causes of oocyte degeneration in the fetal and early postnatal ovary, this takes place through apoptotic PCD mechanisms. Actually, several reports in a variety of species, including human, have identified dying fetal oocytes using typical apoptotic markers such as terminal deoxynucleotidyl transferase dUTP nick end (TUNEL) labelling, cleaved poly (ADP-ribose) polymerase-1 (PARP-1), plasma membrane Annexin $\mathrm{V}$ protein and active caspases. Moreover, gene ablation experiments and the analyses of the expression of members of the $\mathrm{Bcl}-2$ family ( $\mathrm{Bcl}-2$, Bax, $\mathrm{Bcl}-\mathrm{x}$ ) carried out mainly in mouse oocytes, established a crucial role of these pro- or anti-apoptotic genes in oocyte death (for a review, see Klinger and De Felici, 2011) (Fig. 1). It is to be noted, however, that the classical morphological description of cell apoptosis such as chromatin margination and nucleus and cytoplasm fragmentation, is not applicable to dying oocytes, likely for the peculiarity of chromosome and cytoskeleton organization during meiosis. Moreover, the TUNEL staining, generally used for detecting DNA fragmentation resulting from apoptotic cascade, at least in vivo and at early stages of meiotic prophase I, does not seem to be a reliable marker for apoptosis in all fetal oocytes (for references, see De Felici and Klinger, 2011). Recent papers on the buffalo and cattle and mouse fetal oocytes as well, also led to such conclusion, focusing on PARP-1 as a more suitable marker of oocyte apoptosis (Santos et al., 2013; Ene et al., 2013).

\section{Apoptotic pathways}

It is not known if the multiple causes of oocyte death reported above take different or the same PCD molecular pathways. In this regard, no progresses were obtained in the identification of the proapoptotic pathways activated following the withdrawal of the growth factors reported to protect mouse or human fetal oocytes from death (KL, LIF, IGF-1, NT4/5 and IL-1, see Klinger and De Felici, 2011). The results by Gawriluk and coll. (Gawriluk et al., 2011), reported above, indicate, however, that fetal oocytes are prone to activate autophagy. Actually, this could occur in the absence of adequate growth factor amount to preserve oocytes from death. Nevertheless, despite this, most oocytes undergo apoptosis likely because under prolonged starvation, autophagy turns into cell death effector. This might happen both through typical autophagic lysosomal activity but also through apoptotic pathways. In fact, beclin 1 is able to bind BCL2, BCL-X or MCL1 (myeloid cell leukemia-1) and in this way favour the action of proapototic protein such as BAX. Actually, the balance between the anti-and proapoptotic proteins BCL-X and BAX was shown to be an important regulator of the oocyte death (for a review, see, Klinger and De Felici, 2011). A possible scenario is that, depending on different conditions, oocytes, can undergo PCD by autophagy or BCL-X/BAX rheostat. Under growth factor deprivation, in the absence of effective autophagy (Gawriluk et al., 2011), the $\mathrm{BCL}-\mathrm{X} / \mathrm{BAX}$ rheostat might lead to apoptosis, while in the absence of BAX, autophagy might induce oocyte to death (De Felici et al., 2008; Rodrigues et al., 2009) (Fig. 2).

Other players appear in the PCD affecting oocyte as they reach the diplotene block and primordial follicles are assembled (Fig. 2). At this stage, according to Jones and Pepling (2013), the myeloid cell leukemia-1 (MCL-1), previously reported to be expressed at high level in human fetal oocytes (Hartley et al., 2002), becomes 
the prevalent member of the BCL-2 family proteins able to modulate the survival of the mouse oocytes. Moreover, at this time, the mouse oocyte death seems to be triggered by increased level of the proliferating cell nuclear antigen (PCNA) (Xu et al., 2011). The exact mechanism by which this protein that acts as a scaffold to recruit proteins involved in DNA replication, DNA repair, chromatin remodelling and epigenetics, triggers apoptosis of oocytes is unknown. It seems likely, however, that PCNA participates to the checkpoint activated at this stage to eliminate oocyte with DNA damage (see below). In any case, PCNA-mediated oocyte apoptosis depends on the availability of the inhibitor of growth 1 (ING1), a member of an evolutionarily conserved family of tumor suppressor proteins, and results in increasing Bax, casp-3 and Par6 and decreasing $\mathrm{Bcl}-2$ gene expression (Xu et al., 2011). Interestingly, the oocytes were protected from the PCNA dependent apoptosis by the micro RNA 376a that, by directly binding to the 3' untraslated region (UTR) of the PCNA mRNA, inhibits its translation (Zhang et al., 2014).

Robust data support the notion that PCD occurring early after birth in primordial oocytes is related to their quality. Actually, oocytes from mice deficient in several proteins involved in chromosome crossover, synapses or DNA repair such as ATM, SPO11, RAD51, MSH5, Mei4 and TRIP13, are eliminated after birth for defects in such processes (for references, see De Felici and Klinger, 2011). The timing of death appears delayed for several days after the defect occurring in the oocytes and coincides with the maximum level of PCNA and a rapid increase in TAp63 expression (Suh et al., 2009). Bolcun-Filas et al., (2014), proposed that in mouse oocytes this DNA damage response pathway involves signalling of ataxia telangiectasia and Rad3-relate (ATR) to checkpoint kinase 2 (CHK2), which in turn signals to both TAp63 and p53. The involvement of both genes in such DNA checkpoint was suggested by the observation that $p 53$ deficiency did not rescued Trip13-/-oocytes while TAp63 deletion did not completely protected primordial oocytes from death induced by irradiation. Interestingly, a further control level of TAp63 activity is phosphorylation by ataxia telangiectasia mutated (ATM) kinase or dephosphorilation by a calyculin A-sensitive Ser/Thr protein phosphatase (Kim and Suh, 2014).

At this stage, the oocyte execution to death might depend primarily on caspase 9, and at lesser extent caspase 7 (Ene et al., 2013). It was already known that caspase 9 was expressed in fetal oocytes (Kuida et al., 1998). More recently, Ene et al., (2013) found that the mitochondrial apoptotic pathway mediated by caspase 9 is constitutively activated in fetal mouse oocytes throughout prophase I and operates specifically for the elimination of oocytes with meiotic errors during a narrow window between 18.5 and 21.5 days post coitum (dpc). Endogenous apoptosis inhibitors, particularly X-linked inhibitor of apoptosis protein (XIAP), may inhibit the activity of caspase 9 and allow quality oocytes to survive. From these observations, it seems likely that different caspases, as example caspase 2, in previous stages (Bergeron et al., 1998; Lobascio et al., 2007), can mediate oocyte loss depending on the period of development and experimental conditions.

Interestingly, the capability of the AKT kinase to inhibit XIAP ubiquitination and degradation by phosphorylating residue serine 87 , might link the oocyte quality control to the availability from the surrounding somatic cells of specific growth factor such as KL and IGF-1. Actually, only the oocytes with elevated growth factor-dependent AKT activity might be able to efficiently repair DNA damage and avoid apoptosis. The elongation factor 2 kinase (eEF2K) might be also involved in decreasing the level of the short lived XIAP by inhibiting
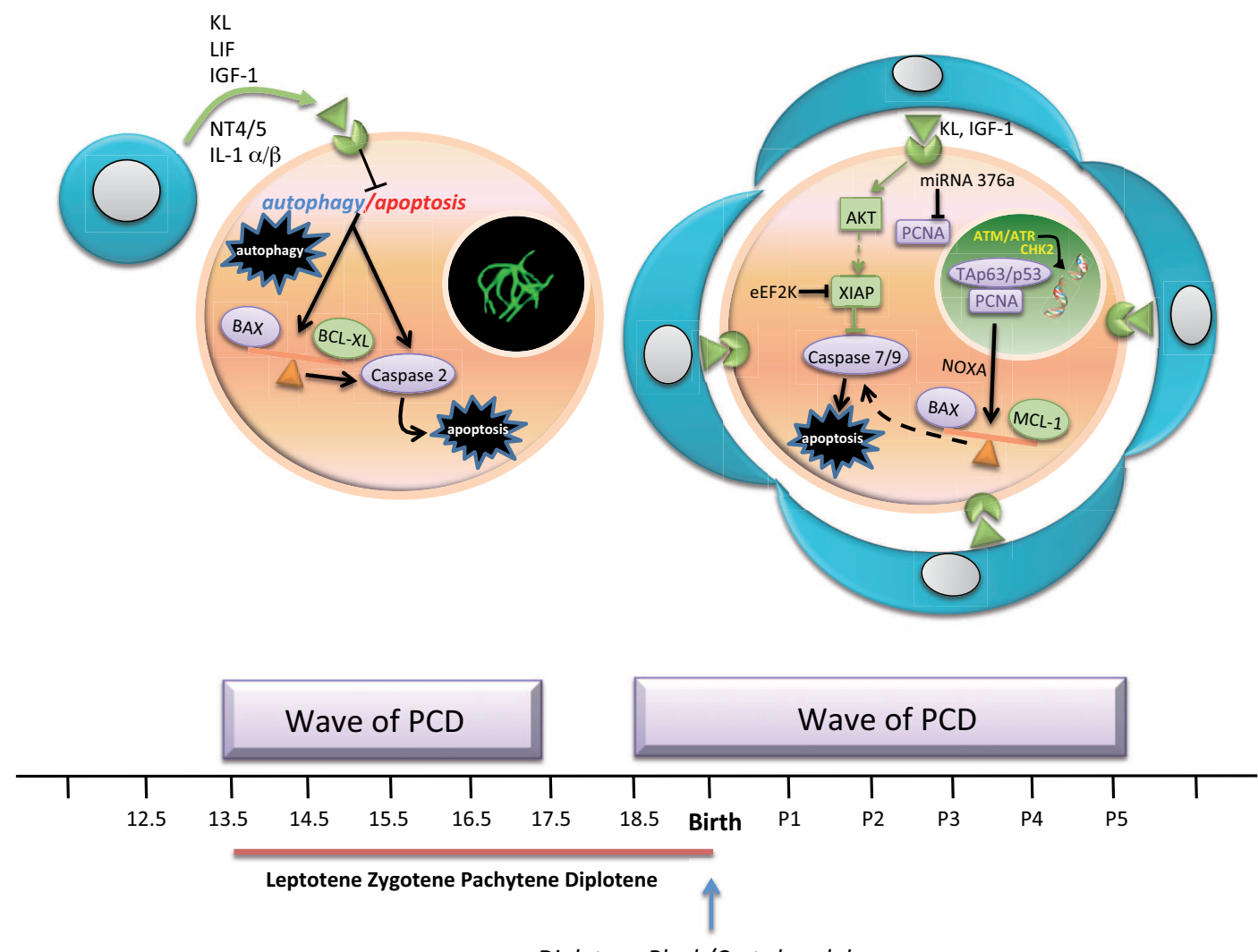

Diplotene Block/Cysts breakdown
Fig. 2. Schematic drawing of known and hypothetical cross-talking pathways of PCD in mouse fetal oocytes. A first wave of oocyte apoptosis occurs during the early stages of meiotic prophase l; a second wave takes places when oocytes reach the diplotene/dictyate block and are enclosed within pre-granulosa cells to form primordial follicles. Cross-talk between autophagy and apoptosis BAX/BCL-Xdependent pathways modulated by growth factor availability, regulates the first wave; the second one, activated by a DNA damage checkpoint primarily depends on p63/p53 and PCNA proteins, probably converging on the rheostat BAX/MCL-1 and the activity of caspase 7 and 9; growth factors might modulate also these pathways by holding on caspase 9 activity. 
global protein synthesis in defective oocytes (Chu et al., 2014).

Finally, it is to be mention a paper that provides an elegant in vitro model for live imaging studies of peri-and postnatal dynamics of oocytes in normal and genetically altered mice (Lin et al., 2014). The authors using the Figla promoter to express Cre recombinase, established $\mathrm{mEGFP} / \mathrm{mTomato}$ reporter mice with green oocytes and red somatic ovarian cells. When these mice were crossed into the Figla null background to accelerate perinatal oocyte loss, live imaging of cultured newborn ovaries provides evidence that few oocytes egress and the vast majority disappeared within the confines of the ovary. Investigations with TUNEL staining and caspase inhibitors confirmed apoptosis as the major process of oocyte elimination at perinatal stages in female mice.

\section{Conclusions and perspectives}

From the previous and the more recent works reviewed here, it appears that mammalian fetal oocytes face several challenges to survive. Different forms of PCD and pathways can mediate oocyte loss, depending on the period of development and experimental conditions. An extraordinary level of DNA DSB tolerance characterizes oocytes during the first stages of meiotic prophase I. It is likely that fetal oocytes withstand such high-level DNA double-strand breaks (DSB) by virtue of an efficient DNA repair machine involved in homologous recombination and the absence $(p 63, p 73)$ or low activity (p53) of transcription factors able to promote apoptosis in the presence of DNA damage. In this regard, we hypothesize that fetal oocytes throughout all stages of prophase I require the support of several growth factors to accomplish such activities. The shortness of nutrients/growth factors might activate protective autophagy but this can turn into their degeneration if starvation is prolonged. Actually, the key to understand fetal oocyte PCD could be in clarifying the relationships among growth factor signalling (mainly AKT cascade), apoptotic and autophagic proteins that seem coexist in these cells. Actually, in fetal oocytes, the pro-survival function of BCL-2 proteins, mainly BCL-X and MCL-1, besides to antagonize $\mathrm{BAX}$, might cross talk with autophagic pathways. More clearly, the activation of a p63/p53-and PCNA-dependent checkpoint plays a major role in eliminating defective oocytes when they reach the diplotene stage and are enclosed by pregranulosa cells. The resulting apoptotic pathways seem to converge first on NOXA/ BAX and finally on caspase 9 activation or directly on caspase 9 unblock. Actually, the latter appears constitutively active in the fetal oocytes but likely blocked by anti-apoptotic IAP proteins such as XIAP. Since the stability of this short live protein can be modulated by AKT kinase, downstream the activation of several growth factor receptors, the action of growth factors should be investigated also on such process.

\section{References}

BERGERON L, PEREZGI, MACDONALD G, SHI L, SUNY, JURISICOVAA, VARMUZA S, LATHAM KE, FLAWS JA, SALTER JC, HARA H, MOSKOWITZ MA, LI E, GREENBERG A, TILLY JL, YUAN J. (1998). Defects in regulation of apoptosis in caspase-2 deficient mice. Genes Dev 12: 1304-1314.

BOLCUN-FILAS E, RINALDI V D, WHITE M E, SCHIENTI J C (2014). Reversal of female infertility by Chk2 ablation reveals the oocyte DNA damage checkpoint pathway. Science 343: 533-536.

CHU HP, LIAO Y, NOVAK J S, HU Z, MERKIN J J, SHYMKIV Y, BRAECKMAN B P, DOROVKOV M V, NGUYEN A, CLIFFORD P M, NAGELE R G, HARRISON D
E, ELLIS R E, RYAZANOV A G (2014). Germline quality control: eEF2K stands guard to eliminate defective oocytes. Dev Cell. 28: 561-572.

DE FELICI M, DICARLOA, PESCE M, IONAS, FARRACE M G, PIACENTINI M (1999) $\mathrm{Bcl}-2$ and Bax regulation of apoptosis in germ cells during prenatal oogenesis in the mouse embryo. Cell Death Dif 6: 908-915.

DE FELICI M, KLINGER F G (2011). DNA damage and apoptosis in fetal and ovarian reserve oocytes. In Cell death in mammalian ovary (Eds G H Vazquez-Nin, M L Escobar, M De Felici, O M Echeverrìa and F G Klinger) Springer, pp. 143-163.

DE FELICI M, LOBASCIO A M, KLINGER F G (2008). Cell death in fetal oocytes: many players for multiple pathways. Autophagy. 4: 240-242.

ENE A C, PARK S, EDELMANN W, TAKETO T (2013). Caspase 9 is constitutively activated in mouse oocytes and plays a key role in oocyte elimination during meiotic prophase progression. Dev Biol. 377: 213-223.

FLAWS J A, HIRSHFIELD A N, HEWITT J A, BABUS J K, FURTH P A (2001). Effect of $\mathrm{Bcl}-2$ on the primordial follicle endowment in the mouse ovary. Biol Reprod. 64: 1153-1159.

GAWRILUK T R, HALE A N, FLAWS J A, DILLON C P, GREEN D R, RUCKER E B (2011). Autophagy is a cell survival program for female germ cells in the murine ovary. Reproduction. 141: 759-765.

HARTLEY P S, BAYNE R A, ROBINSON L L, FULTON N, ANDERSON R A (2002). Developmental changes in expression of myeloid cell leukemia-1 in human germ cells during oogenesis and early folliculogenesis. J Clin Endocrinol Metab. 87: 3417-3427.

HOLT J E, PYE V, BOON E, STEWART J L, GARCÍA-HIGUERA I, MORENO S, RODRÍGUEZ R, JONES K T, MCLAUGHLIN E A (2014). The APC/C activator FZR1 is essential for meiotic prophase I in mice. Development. 141: 1354-1365.

JONES R L, PEPLING M E (2013). Role of the antiapoptotic proteins BCL2 and MCL1 in the neonatal mouse ovary. Biol Reprod. 88: 46.

KIM D A, SUH E K (2014). Defying DNA double-strand break-induced death during prophase I meiosis by temporal TAp63 $\alpha$ phosphorylation regulation in developing mouse oocytes. Mol Cell Biol. 34: 1460-1473.

KLINGER F G, DE FELICI M (2011). Programmed cell death in fetal oocytes. In Cell death in mammalian ovary (Eds G H Vazquez-Nin, M L Escobar, M De Felici, O $M$ Echeverrìa and $F$ G Klinger) Springer, pp. 125-142.

KUIDA K, HAYDAR T F, KUAN C Y, GU Y, TAYA C, KARASUYAMA H, SU M S, RAKIC P, FLAVELL R A (1998). Reduced apoptosis and cytochrome c-mediated caspase activation in mice lacking caspase 9. Cell. 94: 325-337.

LIN RS, JIMENEZ-MOVILLA M, DEAN J. (2014). Figla-Cre transgenic mice expressing myristoylated EGFP in germ cells provide a model for investigating perinatal oocyte dynamics. PLoS One. 9: e84477.

LOBASCIO A M, KLINGER F G, SCALDAFERRI M L, FARINI D, DE FELICI M (2007) Analysis of programmed cell death in mouse fetal oocytes. Reproduction. 134: 241-252.

MALKI S, VAN DER HEIJDEN G W, O'DONNELL K A, MARTIN S L, BORTVIN A (2014). A role for retrotransposon LINE-1 in fetal oocyte attrition in mice. Dev Cell. 29: 521-533.

PESCE, M, CERRITO, M G, TRAVIA, G, RUSSO M A, DE FELICI, M (1996). In vitro development of growing oocytes from fetal and early postnatal mouse ovaries. Int. Dev. Biol. Suppl. 1: 229-230.

SANTOS S S, FERREIRA M A, PINTO J A, SAMPAIO R V, CARVALHO A C, SILVA T V, COSTA N N, CORDEIRO M S, MIRANDA M S, RIBEIRO H F, OHASHI O M (2013). Characterization of folliculogenesis and the occurrence of apoptosis in the development of the bovine fetal ovary. Theriogenology. 79: 344-350.

SUH E K, YANG A, KETTENBACH A, BAMBERGER C, MICHAELIS A H, ZHU Z, ELVIN J A, BRONSON R T, CRUM C P, MCKEON F (2006). p63 protects the female germ line during meiotic arrest. Nature 444: 624-628.

TILLY J L (2001). Commuting the death sentence: how oocytes strive to survive. Nat Rev Mol Cell Biol. 2: 838-848.

XU B, HUA J, ZHANG Y, JIANG X, ZHANG H, MA T, ZHENG W, SUN R, SHEN W, SHA J, COOKE H J, SHI Q (2011). Proliferating cell nuclear antigen (PCNA) regulates primordial follicle assembly by promoting apoptosis of oocytes in fetal and neonatal mouse ovaries. PLoS One. 6: e16046.

ZHANG H, JIANG $X$, ZHANG Y, XU B, HUA J, MA T, ZHENG W, SUN R, SHEN W, COOKE H J, HAO Q, QIAO J, SHI Q (2014). microRNA 376a regulates follicle assembly by targeting Pcna in fetal and neonatal mouse ovaries. Reproduction. 148: 43-54. 


\section{Further Related Reading, published previously in the Int. J. Dev. Biol.}

Revisiting DNA damage repair, p53-mediated apoptosis and cisplatin sensitivity in germ cell tumors Francesca Cavallo, Darren R. Feldman and Marco Barchi

Int. J. Dev. Biol. (2013) 57: 273-280

http://dx.doi.org/10.1387/ijdb. 130135mb

Causes and consequences of apoptosis in spermatozoa; contributions to infertility and impacts on development R. John Aitken and Mark A. Baker

Int. J. Dev. Biol. (2013) 57: 265-272

http://dx.doi.org/10.1387/ijdb. 130146ja

Life-giving caspases: revealing new roles during mouse embryo preimplantation development Dolores Busso, Calixto Dominguez, Tomas Perez-Acle and Ricardo D. Moreno

Int. J. Dev. Biol. (2010) 54: 857-865

http://dx.doi.org/10.1387/ijdb. 092921db

Mpl receptor defect leads to earlier appearance of hematopoietic cells/hematopoietic stem cells in the Aorta-Gonad-Mesonephros region, with increased apoptosis Maud Fleury, Laurence Petit-Cocault, Denis Clay and Michèle Souyri

Int. J. Dev. Biol. (2010) 54: 1067-1074

http://dx.doi.org/10.1387/ijdb. 103104mf

Apoptosis in Drosophila: compensatory proliferation and undead cells

Francisco A. Martín, Ainhoa Peréz-Garijo and Ginés Morata

Int. J. Dev. Biol. (2009) 53: 1341-1347

http://dx.doi.org/10.1387/ijdb. 072447fm

Key apoptosis regulating proteins are down-regulated during postnatal tissue development

Shane D. Madden, Maryanne Donovan and Thomas G. Cotter

Int. J. Dev. Biol. (2007) 51: 415-424

http://dx.doi.org/10.1387/ijdb. 062263sm
5 yr ISI Impact Factor $(2013)=2.879$

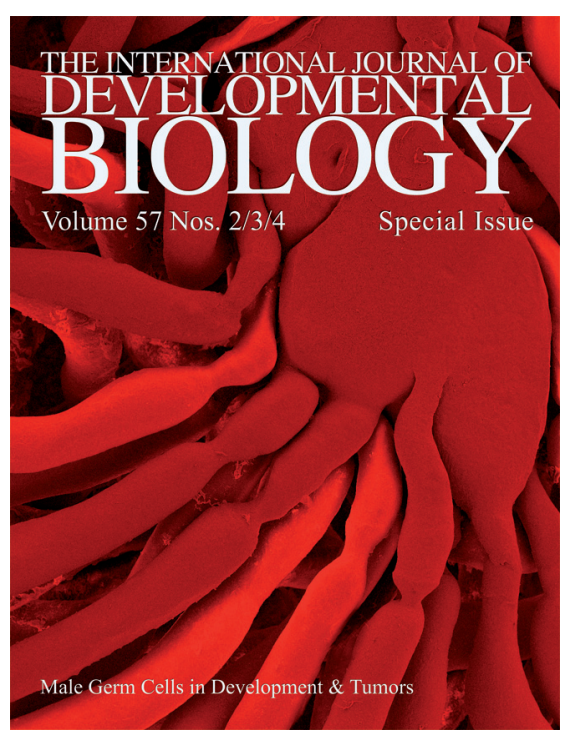

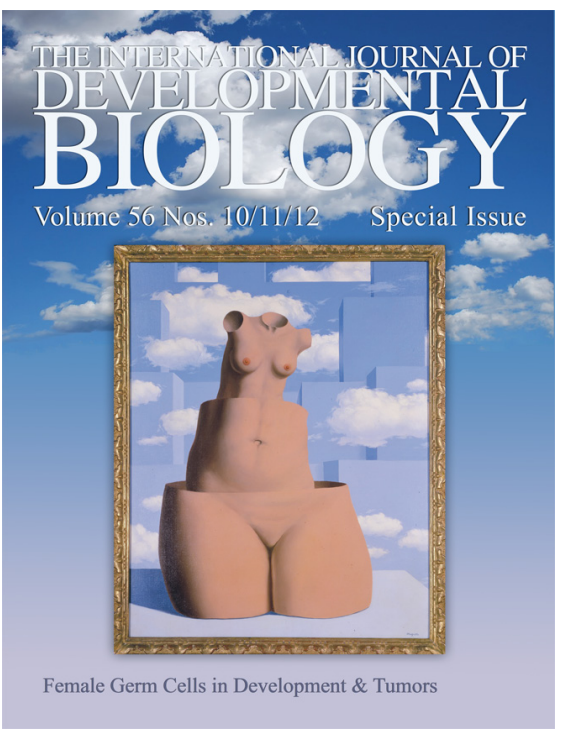

